University of Wollongong

Research Online

Faculty of Social Sciences - Papers (Archive) Faculty of Arts, Social Sciences \& Humanities

$1-1-2017$

The importance of critical life moments: An explorative study of successful women with autism spectrum disorder

Amanda A. Webster

University of Wollongong, awebster@uow.edu.au

Susanne Garvis

University of Gothenburg

Follow this and additional works at: https://ro.uow.edu.au/sspapers

Part of the Education Commons, and the Social and Behavioral Sciences Commons

Research Online is the open access institutional repository for the University of Wollongong. For further information contact the UOW Library: research-pubs@uow.edu.au 


\title{
The importance of critical life moments: An explorative study of successful women with autism spectrum disorder
}

\author{
Abstract \\ Ten women with autism spectrum disorder participated in oral interviews in order to share their \\ experiences since their diagnosis and to discuss the factors that had enabled them to achieve success in \\ different aspects of their life. Participants were encouraged to share their perspectives on their success \\ and to discuss the challenges they encountered in their daily lives and how they overcame these. \\ Interviews were analysed using a narrative-themed approach. Participants indicated that both internal and \\ external factors enabled them to achieve success in different aspects of their lives. These included being \\ an agent of change, a changed identity after diagnosis, experiencing the belief of others in their capability \\ and seeing themselves as a mentor to others. Their experiences with overcoming obstacles in their lives \\ enabled them to develop self-efficacy and to shape their own success.

\section{Disciplines \\ Education | Social and Behavioral Sciences}

\section{Publication Details} \\ Webster, A. A. \& Garvis, S. (2017). The importance of critical life moments: An explorative study of \\ successful women with autism spectrum disorder. Autism: the international journal of research and \\ practice, 21 (6), 670-677.
}




\begin{abstract}
Ten women with autism spectrum disorder participated in oral interviews in order to share their experiences since their diagnosis, and to discuss the factors that had enabled them to achieve success in different aspects of their life. Participants were encouraged to share their perspectives on their success and to discuss the challenges they encountered in their daily lives and how they overcame these. Interviews were analysed using a narrative-themed approach. Participants indicated that both internal and external factors enabled them to achieve success in different aspects of their lives. These included being an agent of change, a changed identity after diagnosis, experiencing the belief of others in their capability, and seeing themselves as a mentor to others. Their experiences with overcoming obstacles in their lives enabled them to develop self-efficacy and to shape their own success.
\end{abstract}

\title{
Keywords
}

adults, women, females, autism spectrum disorder, success, self-efficacy 
The importance of critical life moments: An explorative study of successful women with

\section{Autism Spectrum Disorder}

\section{Introduction}

Recent research and autobiographies of women with autism spectrum disorder (ASD) (Davidson, 2008) indicate that women with ASD have unique stories and histories. These accounts suggest that, although women may experience significant challenges throughout their lives, some are still able to achieve significant outcomes (Grandin, 2012). Despite this finding, little is known about the factors that enable women with ASD to achieve success. This paper presents a narrative analysis of the stories of 10 women with ASD in order to identify internal and external factors that allowed them to take charge of their lives and to achieve success.

Autism spectrum disorder (ASD) is a neurodevelopmental disorder that is diagnosed significantly more often in males than in females (Werling and Geschwind, 2013). In recent years, researchers, professionals and individuals with ASD have begun to explore the differing presentation of ASD in girls and boys. Some researchers suggest that girls and boys demonstrate the characteristics of ASD in distinctive ways (Mandy et al., 2012; Kreiser and White, 2014). Two recent reviews of studies comparing males and females on the spectrum point to subtle differences in phenotype demonstrated by women with ASD, and suggest that girls and women with ASD exhibit a greater interest in socialisation, fewer stereotypical and repetitive behaviours, restricted interests in keeping with social and gender norms, and higher levels of mental health and emotional issues (Kirkovski et al., 2013; Van WijngaardenCremers et al., 2014). Attwood (2007) adds that females with ASD often have different coping mechanisms that do males.

Although research suggests that males and females may experience (Baldwin and 
Costley, 2015) and manifest the specific characteristics of ASD differently (Mandy et al., 2012; Lai et al., 2011), less is known about the specific experiences of adult women with ASD (Kirkovski et al., 2013). An exception is a recent study of 82 women with ASD conducted by Baldwin and Costley (2015). These researchers found that women did not exhibit a distinctly unique profile of characteristics, but rather felt that ASD impacted them differently resulting in experiences that were dissimilar from those of their male peers. This study also revealed that many women were disadvantaged due to late diagnosis, and consequently felt they did not receive support to help them understand why there were different.

Similar to the findings of Baldwin and Costley (2015), studies have generally painted a fairly negative picture of the outcomes experienced by adults with ASD. Barnhill (2007) found that the minority of adults with ASD are in fulltime employment. Others are employed at lower level jobs not in keeping with their skills or qualifications. In a recent review of employment outcomes for individuals with ASD, Hendricks (2010) concluded that although many adults with ASD would like to work, employment outcomes are poor. Up to $75 \%$ of the participants in this study reported being unemployed or earning significantly less money than their peers with equivalent skills. Even individuals with postsecondary qualifications reported having difficulty finding and maintaining employment.

Researchers have also explored the accounts of successful adults with ASD to determine how they perceive and quantify their own skills, needs and measures of success. Chamak et al. (2008) examined 20 autobiographical accounts and interviews of adults with ASD to compare their experiences of autism with current scientific and medical representations. The most striking finding was that, in contrast to the medical field which emphasised deficits in social communication and restrictive and repetitive behaviours and interests, all of the individuals felt their unusual perception and information processing as 
well as difficulties in emotional regulation were their core difficulties. All described still having impairments as adults, but felt that their diagnosis was positive, and had led them to develop a greater self-acceptance and understanding of themselves. Interestingly, despite the much larger number of males diagnosed with ASD, the researchers found that a higher percentage of women (56\%) published their reflections of their experience. This research suggests that gathering the insights of adults with ASD is particularly important in understanding the elements that most impact their lives.

Ashby and Causton-Theoharis (2009) examined autobiographical accounts of 7 individuals with ASD (3 women) to examine their understanding of competency and what practices supported them to develop a belief in their own competency. The individuals in this study related they often encountered a tension between what they knew and what they were able to demonstrate. The individuals in the study spoke of frequently encountering low expectations and feeling a burden to prove their competence. This was mitigated in part when people who supported them believed in their abilities.

Ashby and Causton-Theoharis's (2009) study provides a rare attempt to examine what factors helped adults with ASD to develop a belief in themselves as competent individuals, although it did not determine whether these individuals saw themselves as successful or demonstrated self-determination and self-efficacy. In addition, the majority of studies, which have addressed outcomes for adults, have only included a small percentage of women. Given that researchers (Baldwin and Costley, 2015) indicate that women with ASD may have experiences different than males, it is important that research be conducted to determine what outcomes adult women with ASD achieve, and the factors that enable them to be successful and to develop a sense of competence and self-efficacy.

The following study was conducted to explore the lives of women with ASD who view themselves as successful and to examine how they perceive success in their lives. Self- 
efficacy theory was utilised as a lens to examine the factors that enabled them to perceive themselves as successful.

\section{Method}

The study explored the women's experience from a social constructionist perspective that emphasises the social processes by which people develop their social reality and knowledge about that reality in an ongoing way in interaction with others (Cohen et al., 2004). The space captured and communicated the emotional nature of lived experiences (Clandinin and Connelly, 2000) of the women involved as they reflected on being successful.

Participants were recruited through advertisements, which were placed on a university autism community website and two other social media pages sponsored by autism support groups. The study received ethics approval through the Griffith University ethics board (EDN 94/13/HREC). The majority of participants were recruited via a social media site run by a local psychologist specializing in working with women with ASD. The advertisement asked for successful women with a diagnosis of ASD to participate in oral interviews. The term 'successful' was not clarified, as part of the aim of the study was to ascertain the ways in which women with ASD define success.

Ten participants responded and agreed to share their stories. Nine women lived in Australia. One participant, although originally from Australia, lived in the USA. Participants were between 28 and 55 years old. All of the women had a qualification; two held doctorates, one held a master degree, four held a bachelor degree and the rest had a certificate from TAFE. Their employment included working as a public administrator, psychologist, journalist, entertainer, fitness instructor and charity work. Three women were married, two women were in long-term relationships, three women were divorced or separated and the remaining women were single. All had been diagnosed with Asperger Syndrome after the age of 18 and one participant had a comorbid diagnosis of schizoaffective disorder. The sample 
size of 10 was considered adequate for this study as it aligns with Creswell's (1998, p. 64) suggestion of five to 25 participants and Morse's (1994, p. 225) suggestion of at least six participants.

Semi-structured interviews were conducted with the participants. Interview questions were related to the women's life experiences including their experiences pre and post diagnosis, and encompassed different aspects of their lives such as relationships, education and employment. The interviews lasted between 1-2 hours and were audio-recorded and later transcribed for analysis. Interviews were conducted over the phone or through computer video-conference at a time convenient to the participant.

A narrative-themed analysis was conducted. The initial search was for "chunks of interview text about particular themes," that were meaningful and relevant to the study and figured "importantly and repeatedly" (Riessman, 1993: 67). Next, the interpretive devices of broadening, burrowing and restorying were implemented (Connelly and Clandinin, 1990) in order to create the main themes. Broadening can be described as moving from the small picture to the big picture, allowing the set up of relationships and partnerships. Broadening helped to explain the socio political, physical and structural aspects (Craig 2007). Burrowing meant reconstructing events from the point of view of the central participants involved in the research study, supported by the perspectives of those who immediately surround them. This involved listening closely to how individuals connected their life experiences together to make personal sense of them (Craig, 2007). Finally, restorying captured the transitions in how the story was told and retold. The interpretive process allowed for the analysis of the lived experience of the women.

\section{Findings}


Analysis of narratives revealed that the women's perceptions of success were shaped by four key factors. These included being an agent of change, experiencing the belief of others in their capability, changed identity of diagnosis, and seeing themselves as a mentor to others. Short vignettes have been included to provide examples of their voice.

\section{Agents of change}

All of the women saw themselves as agents of change who were able to take positive action when faced with difficulty. As part of this representation of self, the women did not see themselves as a victim or limited by the challenges they faced. Rather they saw themselves as an efficacious female who could bring about their own change. The women's narratives illustrated pivotal moments when they were faced with a crisis, and in which they made a significant choice and took action to change their current direction, and move towards a more positive goal. These decisions had a profound influence on shaping their future selfefficacy and in enabling them to feel successful. Many of the participants faced significant obstacles in their lives such as abusive relationships, loneliness, failure at work or school, or even prison. All, however, at some time in their life, had made at least one key decision to take charge of their life and to create an alternative, and more constructive future.

The women felt they had achieved success in a variety of ways including through their achievements in raising their children, maintaining and thriving in their job, having a healthy relationship with a partner, or completing tertiary study. Through these experiences, they were able to develop strategies such as dealing with people and demands in the workplace or university context, which subsequently empowered them to deal with future challenges experiencing even more success. For example, Janelle commented:

I went to university when I was 18 . And I dropped out because all that negative stuff happened. And then I went back in 2001. So I did the first year of a visual arts degree and then went through and did an Honours degree and a Master's degree. I loved it. 
In other examples, Terry found a sense of achievement by undertaking many charity walks across Australia. Likewise, Mary was able to create her own solutions to help her overcome challenges (i.e. noise and light) when performing on stage, which led her to have a successful career as a singer.

Seeing themselves as agents of change helped the women to be able to remove themselves from 'at risk' situations they encountered in their lives. For some women this included leaving abusive relationships with partners, being able to take control of a negative work or university situation, as well as other traumatic events such as rape, abuse and sexual harassment. Michelle commented:

And then I left, I was very proud of that. I saved the money and I took my kids and got out of there which is something my mother never did. So I was very proud of myself.

For Michelle, her ability to change the situation created strong reinforcement for her positive self-efficacy. Eventually, she was able to create a new path for her life and to find success with a new partner and her children.

\section{Belief of others in their capability}

Many of the women spoke about influential people in their lives who believed in them and subsequently enabled them to believe in themselves. These influential people included family members, university professors, employers, romantic partners, friends and coaches, and were viewed by the women as individuals who possessed knowledge, perspectives, and critical information they felt they were lacking. The women had trust in these individuals to 
help them by giving them the input they needed to act in a specific situation or to improve their skills for further action. This is illustrated by Patty who states:

He (boss) would train me about how to behave in meetings because that bothered him the most and it was something I could take away. We went to lots of meeting together and I would write down the different perspectives and I wouldn't say anything until I got a non-verbal signal. So I knew all the details of the topic and he knew the big picture and we became a brilliant team.

More importantly, these influential individuals (others) instilled the women with a belief that they could achieve goals and be successful in different aspects of their lives. For example, Morgan was asked to join the Australian Breast Feeding Association. Morgan discussed her feeling of success when after experiencing breastfeeding her own children, she was able to volunteer with the Australian Breastfeeding Association to help other mums. She commented:

The joy and the emotion you get out of departing knowledge and experience onto others was really fulfilling for me. Helping other mums that were struggling with things that I had struggled with.

Thus, the women felt that the belief of an influential person persuaded the women with ASD to develop their agency for current and future action.

\section{Changed identity after diagnosis}

All of the women felt that their diagnosis helped them to construct a new identity for themselves. As Judy explains her diagnosis had a significant impact on how she felt about her past issues: 
I was relieved because I said 'this is it'. This has been floating around, not knowing quite what it is. I can't put a name to it. I was quite overwhelmed, emotionally, I cried. It was cathartic because it explained so many of the reasons why I struggled so much as a child and as an adolescent in early adulthood.

In contrast some of the women in this study reported that their diagnosis enabled them to obtain support in their workplace by giving them the confidence to articulate their needs and ask for accommodations that would help them to perform better. Although many of the women spoke of experiencing issues with employment at some point, their renewed sense of identity after diagnosis enabled them to make more effective decisions about their careers. Those women who were not able to obtain the support they needed at work, made decisions to go in a different direction and often charted their own career pathways.

All of the women talked about undergoing an initial period of reflection, readjustment and even slight depression following their diagnosis. For example, Patty stated:

At that time, I was thinking it was all doom and gloom. I went home the next day and fell into a deep depression for a couple of months. I was depressed because everything said it was a lifelong condition and there's nothing you can do about it.

After this initial period of readjustment, however, all of the women spoke of experiencing a new sense of identity, purpose and hope. Many of the women mentioned they worked through this stage by reading the literature on ASD and reading about other individuals with ASD. This enabled them to see that the diagnosis could be a positive influence on their identity as self-efficacy. As Janelle relates, after accessing information on ASD she concluded: 
The Asperger's is part of me...It's part of my character. It's part of who I am. I would not choose a cure...You cannot take half my character away from me because it is who I am. Asperger's is not really a disability. It's just a different way of viewing the world.

\section{Mentor to others}

All of the women spoke of ways in which they had created their own notions of success. Although several of the participants spoke of experiencing early failures such as dropping out of school, or experiencing problematic relationships, they were all able to identify inner qualities which had enabled them to persist in times of difficulty and ultimately to succeed in some way. More importantly, the women's stories clearly demonstrated that they had not let others define their perceptions of themselves as successful. As Robin commented:

I'm of the opinion that most people on the autism spectrum do really well...I am surrounded by people on the spectrum who are fine with relationships, they've got jobs, their lives are going on swimmingly but you'll never hear their stories.

The women also related that through their experiences they had developed the agency to achieve whatever they wanted. Judy commented, "It is really important to have high expectations all the way through. If I had gone through life without holding myself to the same standards as everybody else, I would have achieved less".

Another common thread amongst the narratives was to realise that it was important to recognise your own strengths and to recognise your own successes. Part of this was also realising that you could create your own notions of success. Mary discussed: 
I think it's really important to be true to yourself. With all your encounters in life. People will always think they know you and you should do certain things in a certain way, but there's a happy medium.

The women felt that their ability to focus on a goal was one of the things that helped them most when they encountered problems. When asked about her strengths, Peggy related, "drive, focus, set a goal and will achieve no matter what it takes or how long it takes." The women did not view this ability to stay focused on specific goals as a weakness, but as a particular area of strength, and expressed that going with their strengths had been particularly important for them to achieve success. As one of the participants (Terry) put it, "I don't have to try to be someone else anymore. I don't have to try and fit in... Don't worry about confirming with society, go with your strengths".

The women were also asked to discuss advice they would have for other women with ASD. Many of the women agreed that a diagnosis was important for early help as it allowed a better awareness about themselves as well as others. The women however were aware to not blame the diagnosis, realising that they had the agency to achieve what every they wanted. Judy commented:

It is really important to have high expectations all the way through. If I had gone through life without holding myself to the same standards as everybody else I would have achieved less. It's important to still have expectations and think you can amount to something.

All of the women discussed the importance of earlier diagnosis for girls with ASD, which they felt would help them to improve their self-awareness at an earlier stage. For example, Morgan discussed her feeling of success when, after experiencing breastfeeding her 
own children, she was able to volunteer with the Australian Breast Feeding Association to help other mums. She commented:

The joy and the emotion you get out of departing knowledge and experience onto others was really fulfilling for me. Helping other mums that were struggling with things that I had struggled with.

Another key message was based on the message that women with ASD don't have to be special and can lead ordinary lives just like other people. Julie made this point saying: So often you see things about autism like 'autism is wonderful because I am fine' or 'because Mozarts..and they're people who are either famous or they're awesome but they're not representative of the general population of people with AS. So to see people that are just ordinary. I'm a person with autism and I work part time at Maccas, or I take care of my kids. Rather than these expectations that you have to be some kind of genius.

Overall, the women suggested a reimagining of the roles of women and girls with ASD. This included a fluid understanding of the different roles women take on, including mother, wife, daughter and worker. As Susan asked:

But what if these roles were recast into something that better fit with the way women with ASD see their world? And, in the process, if those different roles were also given the dignity and inherent worth of being considered just as much the norm as the norm itself?

\section{Discussion}

Outcomes for adults with ASD have received an increasing amount of attention in recent years from a variety of sectors. Researchers suggest that adults with ASD often fail to 
achieve at the same level as their neurotypical peers (Henninger and Taylor, 2013). Although definitions of outcomes have varied, much of this research has focused on traditional outcomes such as employment, independent living, and successful relationships, with the implication that these achievements that constitute success. Little is known about the ways in which individuals with ASD, and women in particular, view success or perceive the factors that facilitate their achievement.

Examination of the narratives revealed that the women's experiences and actions when faced with challenges and new information about themselves, gave them a positive sense of identity and constructed their view of self as successful women. The women's narratives also revealed critical factors that helped them develop their sense of success (i.e. an agent of change, a changing identity, the belief of others in their capability, and being able to act as a mentor to others).

Bandura (1997: 3) defines self-efficacy as 'beliefs in one's capabilities to organise and execute the course of action required to produce given attainments'. Self-efficacy is itself influenced by four sources: mastery experiences (gaining competence for a task and having evidence that you can succeed); social persuasion (persuaded by others to believe that you can achieve); modelling or vicarious experiences (learn about own capabilities from observing or reading about others); and emotional and physiological factors (internal physical or emotional states). Through their narratives, the self-efficacy of the women became evident suggesting that self-efficacy theory provides a useful framework for examining the factors and influences that can enable girls and women with ASD to achieve success.

All of the women saw themselves as agents of change who had learned through their experiences that they could meet challenges when they occurred and take positive action for their future needs. Bandura (1997) identified mastery experiences as one of the primary sources of self-efficacy. Bandura explains that when people encounter challenges and are 
able to master these challenges, this experience becomes a mastery experience, which is very powerful in shaping their self-efficacy for future difficulties. By gaining positive reinforcement from the decisions they had made when faced with problems in their lives, the women in this study were able to cultivate their sense of self-efficacy, thereby increasing their overall self-confidence that they could deal with future obstacles if and when they arose. The women also spoke about the importance of influential people in their lives who believed in them. Another of Bandura's (1997) sources of self-efficacy, social or verbal persuasion occurs when another person provides verbal communication or feedback that enables an individual to believe in themself. Previous research (van Dinther et al., 2011) suggests that verbal persuasion is most apt to influence an individual's self-efficacy when the person who is providing the information is viewed as knowledgeable and reliable.

The women in this study were able to develop a sense of competence when influential individuals in their lives communicated a belief that they could achieve specific goals and be successful in different aspects of their lives. Researchers (Ashby and Causton-Theoharis, 2009; Biklen and Burke, 2006) have highlighted the significant impact that presumed competence can have on individuals with ASD. In the present study, when significant people in their lives presumed their competence to achieve their goals and succeed in different areas (i.e. education, employment, motherhood), the women in this study developed an improved sense of their own abilities and increased their overall self-efficacy.

In addition to mastery of experience and social persuasion, Bandura (1997) outlines two other sources of self-efficacy; physiological factors and vicarious experience. Vicarious experience occurs when an individual is positively influenced to develop self-efficacy by seeing people who are similar to them succeed. Vicarious experience can also be gained through reading or watching videos as well as direct observation of people in similar contexts overcoming obstacles in their lives. All of the women spoke about their diagnosis as a pivotal 
point, which sparked them to seek out new information, which would give them a greater sense of themselves. They felt that both through their reading about ASD and through examining the experiences of other men and women with ASD, they were able to develop a better self-awareness and confidence.

This finding is consistent with Stephen Shore's assertion that greater self-awareness of individuals with ASD can create increased ability to self-advocate (2004). For the participants in this study, diagnosis gave them a greater self-awareness of who they were, providing them with a stronger and more positive emotional state, which Bandura (1997; 2012) describes as an important contributor to self-efficacy.

Physiological factors are those internal qualities and physical and emotional states that an individual may experience when faced with a difficult situation or challenging task. It is the individual's perception of these factors and the manner in which they view them as either an incentive or a barrier to action that is important. Many of the women related that they were very focused and goal driven. The ability to concentrate on specific items or details to a heightened degree has been acknowledged as a characteristic of many individuals with ASD (Happé and Frith, 2006). In a study comparing males and females with ASD, Lai et al. (2011) found that girls had a greater sense of self-awareness and understanding of their 'autistic traits' than did males. Similarly, the women's narratives in the current study indicate that rather than being a limitation, self-awareness about their characteristics can actually help females with AS to overcome obstacles and to achieve outcomes and experience success. This also suggests that with encouragement, females with ASD can utilise their strengths and passions to help them design alternative solutions to problems.

As the women in this study developed a stronger sense of identity, they began to see that they could also become role models for other females with ASD. Moving into the role of mentor for other young women with ASD also became a physiological factor in increasing 
the women's sense of emotional wellbeing and served as a pivotal point for helping them to develop their sense of belonging and contributing to society. Thus, their vicarious experiences and improved emotional state empowered them and increased their self-efficacy to help others who shared similar issues

\section{Implications}

Based on the women's narratives, it could be argued that girls and women with ASD actually benefit from facing challenges in their life. Moreover, removing these challenges may actually prevent them from developing the self-efficacy to engage in problem solving as adults. Previous research (Ashby and Causton-Theoharis, 2009) indicates that when adults with ASD are assumed to be incompetent, they can become exhausted with the effort of constantly proving their skills. Biklen and Burke (2006) assert that presuming incompetence creates poorer skills in individuals with disabilities, whereas presumed competence and high expectations, can actually prompt individuals to believe they can achieve, and thus to develop their skills to do so. Similarly, the findings of this study indicate that providing females with ASD with supportive environments and presenting them with specific challenges at different stages of their life, may be a key strategy to enabling them to develop the skills and selfefficacy they will need to tackle bigger obstacles in their future.

The question of whether diagnosis has a negative or positive impact on individuals has been debated by many people. Studies have shown that parents may be reluctant to seek a diagnosis for their child for fear of them being labelled and stigmatised by others (Russell and Norwich, 2012). By reflecting on the information they gathered as well as the experiences of others in their situation, the women in this study viewed their diagnosis as a positive experience in which there were able to create a new empowered and self-efficacious identity for themselves. It is perhaps this aspect of their character, which reveals the most about why they saw themselves as successful. Rather than becoming limited by their 
diagnosis, the women felt freed from the constraints of needing to be like everyone else, and to discover their own unique strengths. This finding also has implications for parents of children with ASD, who often struggle to envision a positive future for their children following their diagnosis (Keenan et al., 2010) and feel that. Parents often report the diagnostic process is extremely stressful, and they are provided with little information or positive information about the diagnosis of autism and what it means for their child. In contrast, the narratives in this study indicate that rather than treating the diagnosis of ASD as something that will limit their child's future, individuals can gather information and use the experiences of others to help them use their diagnosis to construct a more positive sense of self.

\section{Limitations}

In the current study, the stories of successful women with ASD were gathered in order to identify factors they associated with their achievement of success and to examine the experiences of women with ASD as unique from their male counterparts. It should be noted, however, that this study focused solely on women and therefore comparisons cannot be made to how their experiences may be similar or different to those of their male peers. To date, this is one of the few studies that has explored outcomes for adults with ASD through the voice of the individuals themselves. Future research is needed to gather the stories of men with ASD in order to determine whether they define success in similar ways and whether the factors that enable them to achieve success are similar or different than women with ASD. In addition, this study focused solely on women who viewed themselves as successful and recognises that their views of factors contributing to their success may not be the views of others. The results of this study could be further extended in future research by comparing the perceptions of adults with ASD who see themselves as successful with the views of those who do not. Most importantly, as success was defined by participants and not through a specific definition, it is 
possible that not all of the participants would be viewed as "successful" using traditional measures. Additionally, as limited research has examined the specific experiences of "successful" individuals with ASD, the intent of this study was merely to explore the perceptions of the individuals themselves in order to identify potential factors that helped them to achieve. Further research using more statistical measurement will be needed to determine the exact correlations of internal and external factors with specific outcomes.

\section{Conclusion}

The purpose of this study was to explore the narratives of women with ASD who viewed themselves as successful in order to identify the factors that had enabled them to achieve success. All of the women had a very positive sense of themselves and often defined their success in very non-traditional ways. Probably the most striking finding was that the women in this study refused to see themselves as victims. In contrast, they felt the decisions they had made when faced with particularly difficult challenges, and the manner in which they had constructed a new sense of identity following their diagnosis with ASD had enabled them to become self-efficacious and successful women. Across the stories there is a message of hope and positivity, showing women with ASD can lead successful and productive lives within society. 


\section{References}

Ashby CE and Causton-Theoharis JN. (2009) Disqualified in the human race: a close reading of the autobiographies of individuals identified as autistic. International Journal of Inclusive Education 13: 501-516.

Attwood T. (2007) The complete guide to Asperger's syndrome, London: Jessica Kingsley Publishers.

Baldwin S and Costley D. (2015) The experiences and needs of female adults with highfunctioning autism spectrum disorder. Autism.

Bandura A. (1997) Self-efficacy: the exercise of control, New York: W.H. Freeman.

Bandura A. (2012) On the Functional Properties of Perceived Self-Efficacy Revisited. Journal of Management 38: 9-44.

Barnhill G. (2007) Outcomes in adults with Asperger syndrome. Focus on Autism and Other Developmental Disabilities 22: 116-126.

Biklen D and Burke J. (2006) Presuming Competence. Equity \& Excellence in Education 39: 166-175.

Chamak B, Bonniau B, Jaunay E, et al. (2008) What can we learn about autism from autistic persons? Psychotherapy and Psychosomatics 77: 271-279.

Clandinin DJ and Connelly FM. (2000) Narrative inquiry, San Francisco: Jossey-Bass.

Cohen L, Duberley J and Mallong M. (2004) Social constructionism in the study of career: Accessing the places that other approaches cannot reach. Journal of Vocational Behavior 64: 407-422.

Connelly FM and Clandinin DJ. (1990) Stories of experience and narrative inquiry. Educational researcher 19: 2-14. 
Craig C. (2007) Story constellations: A narrative approach to situating teachers' knowledge of school reform in context. Teaching and Teacher Education 23: 173-188.

Davidson J. (2008) 'In a World of her Own...': Re-presenting alienation and emotion in the lives and writings of women with autism. Gender, Place \& Culture 14: 659-677.

Grandin T. (2012) Different... Not Less: inspiring stories of achievement and successful employment from adults. Future Horizons.

Happé F and Frith U. (2006) The weak coherence account: Detail-focused cognitive style in autism spectrum disorders Journal of Autism and Developmental Disorders 36: 5-25

Hendricks D. (2010) Employment and adults with autism spectrum disorders: Challenges and strategies for success. Journal of Vocational Rehabilitation 32: 125-134.

Henninger NA and Taylor JL. (2013) Outcomes in adults with autism spectrum disorders: a historical perspective. Autism 17: 103-116.

Keenan M, Dillenburger K, Doherty A, et al. (2010) The experiences of parents during diagnosis and forward planning for children with autism spectrum disorder. Journal of Applied research in intellectual disabilities 23: 390-397.

Kirkovski M, Enticott PG and Fitzgerald PB. (2013) A review of the role of female gender in autism spectrum disorders. Journal of Autism and Developmental Disorders 43: 25842603.

Kreiser NL and White SW. (2014) ASD in females: are we overstating the gender difference in diagnosis? Clin Child Fam Psychol Rev 17: 67-84.

Lai MC, Lombardo MV, Pasco G, et al. (2011) A behavioral comparison of male and female adults with high functioning autism spectrum conditions. PLoS One 6: e20835.

Mandy W, Chilvers R, Chowdhury U, et al. (2012) Sex differences in autism spectrum disorder: evidence from a large sample of children and adolescents. J Autism Dev Disord 42: 1304-1313. 
Riessman CK. (1993) Narrative analysis, Newbury Park, CA: Sage Publications.

Russell G and Norwich B. (2012) Dilemmas, diagnosis and de-stigmatization: parental perspectives on the diagnosis of autism spectrum disorders. Clin Child Psychol Psychiatry 17: 229-245.

Shore S. (2004) Using the IEP to build skills in self-advocacy and disclosure. In: Shore S (ed). Shawnee Mission, KS: AAPC Publshing, 65-106.

van Dinther M, Dochy F and Segers M. (2011) Factors affecting students' self-efficacy in higher education. Educational Research Review 6: 95-108.

Van Wijngaarden-Cremers PJ, van Eeten E, Groen WB, et al. (2014) Gender and age differences in the core triad of impairments in autism spectrum disorders: a systematic review and meta-analysis. J Autism Dev Disord 44: 627-635.

Werling DM and Geschwind DH. (2013) Sex differences in autism spectrum disorders. Current Opinion in Neurology 26: 146-153. 